\title{
Henry Stommel and physical oceanography since 1945
}

\section{K.F. Bowden}

Evolution of Physical Oceanography. Edited by Bruce A. Warren and Carl Wunsch. Pp.623. ISBN 0-262-23104-2. (MIT Press: 1981.) \$37.50, £23.25.

THIS volume is a tribute, on the occasion of his sixtieth birthday, to Henry Stommel who has been a pre-eminent figure in the development of physical oceanography since the Second World War. $\mathrm{He}$ is probably best known for showing, in an early paper published in 1948 , that the intensification of currents on the western side of an ocean is due to the variation of the Coriolis parameter, which expresses the effect of the Earth's rotation, with latitude. This is demonstrated clearly by the relatively narrow, fast-flowing Gulf Stream in the North Atlantic and the Kuroshio in the North Pacific Ocean, but it is a dynamical feature of deep currents as well.

\section{IMAGE UNAVAILABLE FOR COPYRIGHT REASONS}

\section{Henry Stommel}

Stommel has subsequently made remarkable contributions to practically every aspect of physical oceanography, from mixing in estuaries to the world-wide deep circulation of the oceans. His work has been characterized by its physical insight, expressed in terms of the simplest dynamical models, which others have developed in greater mathematical detail. $\mathrm{He}$ has also played a leading part in the move to direct field work in oceanography away from the survey of geographical areas to the study of physical processes.

In their preface the editors explain why, instead of the traditional Festschrift, this volume takes the form of a series of broad, comprehensive surveys of aspects of oceanography with which Stommel has been concerned. Together they present a most valuable picture of the evolution of physical oceanography over the past 35 years and its present status. The surveys are preceded by short contributions from five former colleagues, giving an appreciation of Henry Stommel and his work.
The main body of the book is comprised of 18 chapters grouped into four parts. The first, on the general ocean circulation, is the longest. It has surveys of the deep circulation of the world ocean by B.A. Warren, on water masses by L.V. Worthington, the mid-depth circulation by J.L. Reid and the Gulf Stream System by N.P. Fofonoff. In his chapter on the dynamics of large-scale ocean circulation, G. Veronis gives a comprehensive account of the vast amount of theoretical work in this field over the past 30 years. Equatorial currents are clearly described in observation and theory by A. Leetmaa, J.P. McCreary and D.W. Moore. The chapter on estuarine and continental-shelf circulation in the Middle Atlantic Bight, by R.C. Beardsley and W.C. Boicourt, is of wider interest than its title might suggest, as the treatments and results are applicable to many other areas.

Part Two deals with physical processes in oceanography. The first chapter, by J.S. Turner, is on small-scale mixing processes and is followed by that of W. Munk on internal waves and small-scale processes. Long waves and ocean tides are reviewed by M.C. Hendershott, while C. Wunsch discusses the low-frequency variability of the sea, a feature which has long been recognized but has only recently come to be studied with a thoroughness approaching that with which meteorologists have treated the atmosphere. In the only contribution of a biological nature, J.H. Steele discusses the interaction of physical, biological and ecological processes in the distribution of organisms. W.V.R. Malkus rounds off this section with a chapter on the amplitude of convection.

The practical oceanographer will welcome Part Three, "Techniques of Investigation", which opens with a good review of instrumentation and the design of experiments by D.J. Baker. W.S. Broecker discusses geochemical tracers and ocean circulation, dealing mainly with the use of radioisotopes, particularly the data from GEOSECS (Geochemical Ocean Sections Studies). The use of laboratory models in the study of ocean circulation is described by A.J. Faller. In the final section on ocean and atmosphere, $\mathbf{H}$. Charnock surveys the topic of air-sea interaction, while J.G. Charney and G.R. Flierl describe ocean analogues of largescale atmospheric motions, concentrating mainly on transient motions.

In a volume of this kind there is bound to be a certain unevenness among the contributions, although here the treatment is more consistent than in most collective works. All chapters are of high quality and comprehensive in scope, the variations being in depth and in the amount of mathematical detail in the chapters on theoretical topics. This volume has succeeded admirably in its purpose of paying tribute to a great oceanographer and providing a comprehensive and inspiring survey of physical oceanography today.

K.F. Bowden is Professor of Oceanography at the University of Liverpool.

\section{Surface tension}

\section{Peter Schofield}

Statistical Mechanics of the Liquid Surface. By Clive A. Croxton. Pp.368. ISBN 0-4712-7663-4. (Wiley: 1980.) £25, \$68.75.

THE first thing to be said about this volume is that the title is wrong. The book is mainly concerned with the molecular theory of liquid surfaces, that is with methods of calculation of the properties of liquidvapour interfaces either from the intermolecular forces and molecular distribution functions (the Kirkwood-Buff approach) or, to a lesser extent, from the old Van der Waal's theory and its modern counterpart in terms of the density gradients and density fluctuations (the Yvon-Triezenberg-Zwanzig approach). In both cases, the derivation from statistical mechanics is given in a manner which the uninitiated reader will find difficult to follow.

The fundamental question about surface tension is whether indeed it has an intrinsic value for a given fluid. The width of the interface is determined by the amplitude of thermal capillary wave fluctuations, which is unbounded in the limit of infinite volume and zero gravity since there is then no cost in free energy in a rotation of the whole system. It is on this quicksand that the molecular theory is built!

Nevertheless, considerable success has been achieved in predicting the properties of the liquid-vapour interface by ignoring such problems, and Clive Croxton has done a service in bringing together this review, with a comprehensive bibliography, of calculational methods for several types of fluid. Following two introductory chapters, the subjects inciude the surfaces of molecular, metallic and quantum liquids, liquid crystals and polymer adsorption at solvent surfaces. The question of molecular orientation in an interface and surface potentials is of considerable practical importance, and in this respect there is a good chapter on water.

As in many fields of physics and physical chemistry, computer simulation methods have a major role to play in bridging the gap between theory and experiment. On 